\title{
Ozurdex for the Treatment of a Patient with Birdshot Chorioretinopathy
}

\author{
Elad Moisseiev Ala Moshiri \\ UC Davis Eye Center, University of California Davis, Sacramento, Calif., USA
}

\section{Key Words}

Birdshot chorioretinopathy $\cdot$ Ozurdex $\cdot$ Dexamethasone $\cdot$ Vitritis

\begin{abstract}
We report a 57-year-old patient with birdshot chorioretinopathy $(B C R)$ who was treated with bilateral Ozurdex injections. The patient's vitritis resolved, and visual acuity improved following this treatment. This is only the second case report focused on the treatment of BCR with Ozurdex and the first to report its use for treating vitritis. A concise review of the literature on the use of intravitreal steroids for this disease is provided. This case serves to report the clinical usefulness of Ozurdex in treating posterior vitritis associated with $B C R$ even in the absence of macular edema.

(C) 2015 S. Karger AG, Basel
\end{abstract}

\section{Introduction}

Birdshot chorioretinopathy (BCR) is a relatively rare cause of posterior uveitis, which is typically bilateral and may cause vitritis, retinal vasculitis, and cystoid macular edema (CME) [1]. The pathogenesis of BCR is unclear, but it is accepted that it is an inflammatory condition [1-3]. BCR is a chronic progressive disease, which requires prolonged treatment with steroids or immunosuppressive agents [1].

Ozurdex is a slow-release, intravitreal, biodegradable dexamethasone implant that is injected through the pars plana and has been approved by the FDA for the treatment of intermediate and posterior noninfectious uveitis [4]. It has been used successfully for the treatment of a wide variety of causes of noninfectious uveitis [5-7]. Review of the literature revealed only one report focused on the use of Ozurdex in a patient with BCR for the treatment

KARGER125:s $\quad \begin{aligned} & \text { Ala Moshiri, MD, PhD } \\ & \text { UC Davis Eye Center, University of California Davis } \\ & \text { 4860 Y St., suite } 2400 \\ & \text { Sacramento, CA } 95817 \text { (USA) } \\ & \text { E-Mail ala.moshiri@ucdmc.ucdavis.edu }\end{aligned}$


Moisseiev and Moshiri: Ozurdex for the Treatment of a Patient with Birdshot Chorioretinopathy

of CME [8]. We report a patient with BCR who was treated with bilateral Ozurdex injections for the treatment of vitritis.

\section{Case Report}

A 57-year-old man was referred to our clinic for evaluation of bilateral blurred vision and floaters, which had been present for over a year. His past medical history included hypertension, hyperlipidemia, and benign prostatic hyperplasia, all of which were medically controlled. The patient complained of no other symptoms and had no previous ocular history. There was no history of travel, exposure to animals, or insect bites.

On examination, visual acuity was 20/30 in both eyes. Pupils were normal with no relative afferent pupillary defect, and intraocular pressures were normal. Anterior segments were normal, with very mild nuclear sclerotic cataracts OU. Dilated fundus examination revealed +2 vitreous cells and vitreal haze in both eyes, as well as optic disc hyperemia and numerous subtle round hypopigmented spots at the level of the choroid in the posterior poles (fig. 1a). Multiple hypofluorescent spots around the optic discs and along the arcades were demonstrated by fluorescein angiography (fig. 1b) and were even more pronounced by indocyanine green angiography (fig. 1c). Optical coherence tomography demonstrated a normal foveal contour with intact outer retinal architecture with no macular edema (fig. 1d). Multifocal electroretinography revealed moderately reduced cone-mediated function of the posterior poles (fig. 1e). Additional workup included normal complete blood count and chemistry tests, negative antinuclear antibody test, normal c- and p-ANCA levels, negative VDRL, normal angiotensin converting enzyme levels, nonreactive tuberculin skin test and a normal chest CT. HLA-A29 was positive.

The constellation of the patient's clinical and laboratory findings led to the diagnosis of $\mathrm{BCR}$, and the patient was put on systemic immunosuppression therapy. To decrease the vitritis that caused his visual complaints, the patient was treated with an Ozurdex injection in the left eye, and vision improved to $20 / 25$, with marked subjective improvement in overall visual function. Six weeks later, he received an Ozurdex injection to the right eye. The patient's vision improved to 20/20 OD and 20/25 OS, with resolution of vitritis bilaterally. He was followed up for an additional 12 months, with no recurrence or need for additional injections.

\section{Discussion}

The clinical, imaging, and laboratory findings of our patient are highly compatible with the criteria for BCR diagnosis [9]. The finding of a positive HLA-A29 is very supportive of this diagnosis, as this finding occurs in over $95 \%$ of cases $[1,10]$. Due to the chronic and progressive nature of BCR, ocular steroid therapy is a compelling option to reduce the need and possible adverse effects of systemic therapy. Intravitreal injections of triamcinolone have been successfully used for the management of BCR patients, but long-term use may cause complications such as glaucoma and cataract $[11,12]$. Several recent studies reported the use of a sustained-release fluocinolone surgically implanted device (Retisert) for the treatment of BCR, which was effective in reducing ocular inflammation but also associated with a substantial rate of glaucoma, requiring surgical treatment, and cataract formation [13-15].

Review of the literature revealed that no study focused on the treatment of BCR with Ozurdex. One case report described the use of Ozurdex for the treatment of CME in one eye 
Moisseiev and Moshiri: Ozurdex for the Treatment of a Patient with Birdshot Chorioretinopathy

of a patient with BCR [8]. Several patients with BCR were included in a recent retrospective analysis of the use of Ozurdex in patients with noninfectious uveitis [5]; however, there was no specific analysis of this subgroup of patients, and the majority of patients included in that study received the treatment for CME. It should also be noted that in the HURON study, which initially investigated the use of Ozurdex in noninfectious uveitis, the vast majority $(81 \%)$ of patients had intermediate uveitis [4]. Our patient had posterior uveitis without $\mathrm{CME}$, and his visual disturbance was attributed to the presence of vitritis and optic nerve head hyperemia. This case illustrates the clinical efficacy of Ozurdex in the treatment of patients with BCR even in the absence of CME. Furthermore, it is likely that Ozurdex has a better long-term safety profile than both triamcinolone and fluocinolone. We recommend considering Ozurdex in the management of BCR patients with active vitritis, for relief of symptoms and possible reduction in the need for systemic therapy. Further studies will clarify the role of Ozurdex in the context of BCR.

\section{Disclosure Statement}

No author has any proprietary interest in the publication of this report.

\section{Statement of Ethics}

The patient has given his informed consent for this report.

\section{References}

1 Shah KH, Levinson RD, Yu F, et al: Birdshot chorioretinopathy. Surv Ophthalmol 2005;50:519-541.

-2 Gaudio PA, Kaye DB, Crawford JB: Histopathology of birdshot retinochoroidopathy. Br J Ophthalmol 2002;86:1439-1441.

-3 Levinson RD, Du Z, Luo L, et al: Combination of KIR and HLA gene variants augments the risk of developing birdshot chorioretinopathy in HLA-A*29-positive individuals. Genes Immun 2008;9:249-258.

-4 Lowder C, Belfort R Jr, Lightman S, Foster CS, Robinson MR, Schiffman RM, Li XY, Cui H, Whitcup SM; Ozurdex HURON Study Group: Dexamethasone intravitreal implant for noninfectious intermediate or posterior uveitis. Arch Ophthalmol 2011;129:545-553.

-5 Zarranz-Ventura J, Carreño E, Johnston RL, Mohammed Q, Ross AH, Barker C, Fonollosa A, Artaraz J, Pelegrin L, Adan A, Lee RW, Dick AD, Sallam A: Multicenter study of intravitreal dexamethasone implant in noninfectious uveitis: indications, outcomes, and reinjection frequency. Am J Ophthalmol 2014;158:11361145.e5.

6 Tomkins-Netzer O, Taylor SR, Bar A, Lula A, Yaganti S, Talat L, Lightman S: Treatment with repeat dexamethasone implants results in long-term disease control in eyes with noninfectious uveitis. Ophthalmology 2014;121:1649-1654.

7 Bratton ML, He YG, Weakley DR: Dexamethasone intravitreal implant (Ozurdex) for the treatment of pediatric uveitis. J AAPOS 2014;18:110-113.

$>8$ Terrada C, Bruneau S, Perrenoud F, Massin P, Souied E: Role of intravitreal dexamethasone implant in the treatment of birdshot retinochoroidopathy. J Fr Ophtalmol 2012;35:745-748.

-9 Levinson RD, Brezin A, Rothova A, Accorinti M, Holland GN: Research criteria for the diagnosis of birdshot chorioretinopathy: results of an international consensus conference. Am J Ophthalmol 2006;141:185-187.

-10 Kuiper JJ, Van Setten J, Ripke S, Van 't Slot R, Mulder F, Missotten T, Baarsma GS, Francioli LC, Pulit SL, De Kovel CG, Ten Dam-Van Loon N, Den Hollander AI, Huis In Het Veld P, Hoyng CB, Cordero-Coma M, Martín J, Llorenç V, Arya B, Thomas D, Bakker SC, Ophoff RA, Rothova A, De Bakker PI, Mutis T, Koeleman BP: A genome-wide association study identifies a functional ERAP2 haplotype associated with birdshot chorioretinopathy. Hum Mol Genet 2014;23:6081-6087.

11 Martidis A, Duker JS, Puliafito CA: Intravitreal triamcinolone for refractory cystoid macular edema secondary to birdshot retinochoroidopathy. Arch Ophthalmol 2001;19:1380-1383. 
Moisseiev and Moshiri: Ozurdex for the Treatment of a Patient with Birdshot Chorioretinopathy

12 Shah A, Branley M: Use of intravitreal triamcinolone in the management of birdshot retinochoroidopathy associated with cystoid macular oedema: a case study over a three-year period. Clin Experiment Ophthalmol 2005;33:442-444.

13 Bajwa A, Aziz K, Foster CS: Safety and efficacy of fluocinolone acetonide intravitreal implant (0.59 mg) in birdshot retinochoroidopathy. Retina 2014;34:2259-2268.

$>14$ Burkholder BM, Wang J, Dunn JP, Nguyen QD, Thorne JE: Postoperative outcomes after fluocinolone acetonide implant surgery in patients with birdshot chorioretinitis and other types of posterior and panuveitis. Retina 2013;33:1684-1693.

15 Rush RB, Goldstein DA, Callanan DG, Meghpara B, Feuer WJ, Davis JL: Outcomes of birdshot chorioretinopathy treated with an intravitreal sustained-release fluocinolone acetonide-containing device. Am J Ophthalmol 2011;151:630-636.
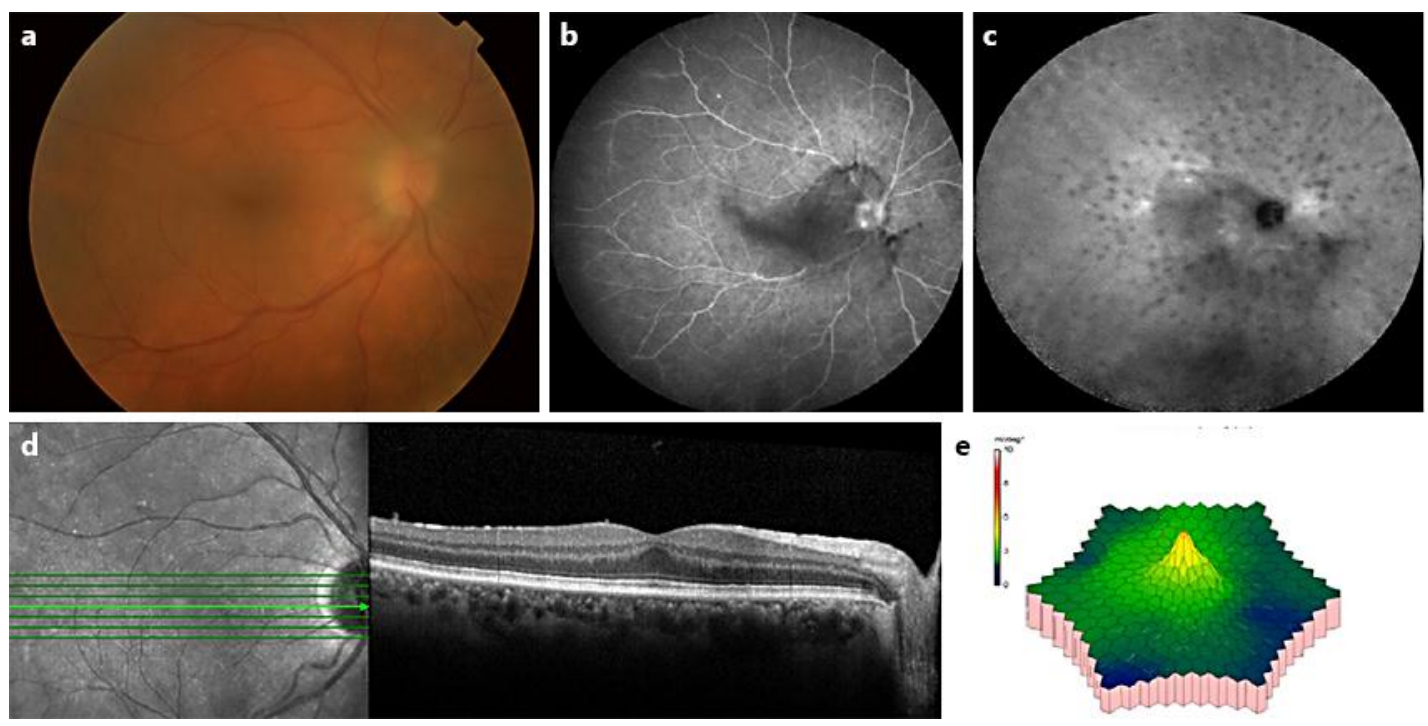

Fig. 1. Ocular findings at presentation. Images of the right eye are shown. The findings were symmetric bilaterally. a Fundus photo notable for disc hyperemia and fine hypopigmented lesions in the posterior pole. The image is blurred by the vitritis. b Fluorescein angiography demonstrating hypofluorescent dots in the posterior pole. c Indocyanine green angiography demonstrating multiple hypofluorescent dots in the posterior pole. $\mathbf{d}$ Optical coherence tomography demonstrating normal foveal contour and outer retinal architecture, and no fluid. e Multifocal electroretinogram showing moderately reduced cone-mediated function of the posterior pole. 